\title{
O PROTOCOLO AGROAMBIENTAL E AS REPERCUSSÕES NO SETOR SUCROENERGÉTICO PAULISTA
}

Gláucia Elisa Mardegan ${ }^{1}$

José Giacomo Baccarin²

RESUMO: Um dos componentes com destaque do agronegócio brasileiro é a gramínea cana-de-açúcar, sendo que o etanol se destacou e com a exportação do açúcar, ocasionou uma grande procura pela matéria-prima destes itens. Estimulando a amplificação desta cultura pelo território do Brasil, com destaque, para a região CentroSul do país, em especial o estado de São Paulo, o maior produtor da cultura, hodiernamente. Este artigo possui o intuito em analisar a dinâmica do setor sucroenergético no estado de São Paulo, quais foram suas modificações na infraestrutura tecnológica, entre os períodos, de 2006 a 2017. Para alcançar esse objetivo foi utilizado um mapeamento das unidades produtivas do setor e os principais grupos que sobressaíram durante este período da análise. Os resultados expõem grande influência do Protocolo Agroambiental da cana-de-açúcar para modificações na dinâmica do setor e nas mudanças tecnológicas do setor, e as características inerentes desta cultura são importantes para o posicionamento das unidades produtivas. O Protocolo Agroambiental veio com o intuito de trazer uma propaganda desta cultura, como uma cultura agrícola com menos danos ambientais, porém, sem nenhum preocuparão com os seus impactos sociais, como o desemprego estrutural.

PALAVRAS-CHAVE: São Paulo; Cana-de-açúcar; mecanização do setor sucroenergético; Protocolo Agroambiental da cana-de-açúcar; expansão.

\section{THE AGRI-ENVIRONMENTAL PROTOCOL AND THE REPERCUSSIONS IN THE SUGAR-ENERGY INDUSTRY IN PAULISTA}

\begin{abstract}
One of the components that stands out in Brazilian agribusiness is the sugarcane grass, with ethanol standing out and with the export of sugar, it caused a great demand for the raw material of these items. Stimulating the expansion of this culture throughout Brazil, with emphasis on the Center-South region of the country, in particular the state of São Paulo, the largest producer of the culture today. This article aims to analyze the dynamics of the sugar-cane industry in the state of São Paulo, what

\footnotetext{
1 Mestra em Geografia pelo Programa de Pós-graduação do Instituto de Geociências da Universidade Estadual de Campinas. Doutoranda do PPGG da UNESP - Rio Claro/SP. E-mail: glaumardegan@gmail.com

2 Docente da UNESP - Campus Jaboticabal/SP e do PPGE da UNESP - Rio Claro/SP. E-mail: jose.baccarin@unesp.br
} 
MARDEGAN, G. E; BACCARIN, J. G. O protocolo agroambiental e as repercussões no setor...

were its changes in the technological infrastructure, between the periods 2006 to 2017 . To achieve this goal, a mapping of the sector's production units and the main groups that stood out during this period of analysis. The results show the great influence of the Agro-Environmental Protocol for changes in the sector's dynamics and in the sector's technological changes, and the inherent characteristics of this culture are important for the positioning of production units. The Agro-environmental Protocol came with the intention of promoting this culture, as an agricultural culture with less environmental damage, however, without any concern with its social impacts, such as structural unemployment.

KEYWORDS: São Paulo; Sugar cane; mechanization of the sugar-energy sector;

Sugarcane Agro-environmental Protocol; expansion.

\section{EL PROTOCOLO AGROAMBIENTAL Y LAS REPERCUSIONES EN EL SECTOR SUCROENERGÉTICO PAULISTA}

RESUMEN: Uno de los componentes que se destaca en la agroindustria brasileña es el pasto de la caña de azúcar, destacando el etanol y con la exportación de azúcar, provocó una gran demanda de la materia prima de estos rubros. Estimular la expansión de esta cultura en todo Brasil, con énfasis en la región Centro-Sur del país, en particular el estado de São Paulo, el mayor productor de la cultura en la actualidad. Este artículo tiene como objetivo analizar la dinámica de la industria de la caña de azúcar en el estado de São Paulo, cuáles fueron sus cambios en la infraestructura tecnológica, entre los períodos 2006 a 2017. Para lograr este objetivo, un mapeo de las unidades productivas del sector y los principales grupos que se destacó durante este período de análisis. Los resultados muestran la gran influencia del Protocolo Agroambiental de la Caña de Azúcar para los cambios en la dinámica del sector y en los cambios tecnológicos del sector, y las características inherentes a este cultivo son importantes para el posicionamiento de las unidades productivas. El Protocolo Agroambiental surgió con la intención de promover esta cultura, como una cultura agrícola con menor daño ambiental, sin embargo, sin preocuparse por sus impactos sociales, como el desempleo estructural.

PALABRAS CLAVE: San Pablo; Caña de azúcar; mecanización del sector sucroenergético; Protocolo Agroambiental de la Caña de Azúcar; expansión.

\section{INTRODUÇÃO}


MARDEGAN, G. E; BACCARIN, J. G. O protocolo agroambiental e as repercussões no setor...

A cana-de-açúcar tem sua trajetória entrelaçada à história da agricultura no território brasileiro, desde o período colonial, em que era presente na Região Nordeste do país, no qual, manteve sua predominância produtiva por séculos. Em 1933, o Governo Federal criou o Instituto do Açúcar e do Álcool (IAA), procurando regulamentar a produção e os investimentos setoriais, além, de tentar manter a participação produtiva das duas grandes regiões, Nordeste e o Centro-Sul. Contudo, a realidade se mostrou mais forte que a determinação pública e o Centro-Sul, com destaque ao estado de São Paulo, foi aumentando sua participação na produção setorial. Uma amostra disso, foi que os empresários paulistas do setor foram muito atuantes na criação, em 1975, do Proálcool, que permitiu, via subsídios financeiros, aumento considerável das agroindústrias e dos canaviais.

Em 1990, com a extinção do IAA, houve a desregulamentação do setor e com as políticas neoliberais, modificou a trajetória de diminuição relativa da produção nordestina, favorecendo a situada no Sudeste. Os empresários de São Paulo reforçaram seu papel hegemônico, continuando a estender suas unidades agroindustriais sucroenergéticas (UAS) e canaviais para o oeste do estado e nos estados vizinhos, no noroeste paranaense, no triângulo mineiro, em terras de Goiás e Mato Grosso do Sul. No presente século, além de capitais dos empresários nacionais, verificou-se o aporte de capitais públicos do BNDES (Banco Nacional de Desenvolvimento Econômico e Social) e de grupos estrangeiros, entusiasmados com as perspectivas altamente favoráveis à produção de biocombustíveis, que se constatou até por volta de 2010 (BACCARIN, 2019).

Em 1975 a cana-de-açúcar ocupava área de 932,0 mil ha no estado, passando para 1.765,3 mil ha, em 1983, havendo um crescimento de $89,4 \%$ no período (IEA, 1977, 2016). Entre 1983 e 2014, a lavoura canavieira continuou 
MARDEGAN, G. E; BACCARIN, J. G. O protocolo agroambiental e as repercussões no setor...

avançando, substituindo áreas de pastagem e de outras lavouras. Em 2006, a área ocupada com cana ultrapassou a das demais lavouras e em 2014 ela se aproximava da área de pastagem do estado e era maior que a soma das áreas com outras lavouras e reflorestamento (BACCARIN, 2019).

Dado este contexto, com o monocultivo da cana em São Paulo, este artigo investiga como as características históricas da exploração desta gramínea pelos empresários do setor e como o Protocolo Agroambiental foi responsável pelas mudanças tecnológicas canavieiras recentes e a configuração do setor sucroenergético no território paulista. O texto se pauta centralmente na análise dos anos de 2006 e 2017, escolhidos para expressar a geografia do período que abrange o Paradigma Agroambiental.

\section{ÁREA DE ESTUDO}

O estado de São Paulo está localizado na região Sudeste do país, possui como estados vizinhos, Minas Gerais, Paraná, Rio de Janeiro e Mato Grosso do Sul. Está dividido em 645 municípios, que estão distribuídos em 53 Regiões Geográficas Imediatas, agrupadas em 11 Regiões Geográficas Intermediárias. As Regiões Geográficas Imediatas são a atualização da divisão regional do Brasil, apresentada pelo IBGE em 2017. Esta atualização de classificação regional do país vem para acompanhar as modificações que ocorreram no território nos últimos anos, tendo um recorte mais próximo da realidade territorial brasileira. Por São Paulo ser um estado com esta junção de concentração de conhecimento científico e de comandos dos grandes grupos do setor sucroenergético, ele foi escolhido como área de estudo, isso será explicado no transcorrer do texto.

Figura1: Mapa do estado de São Paulo com Regiões Geográficas Imediatas 
MARDEGAN, G. E; BACCARIN, J. G. O protocolo agroambiental e as repercussões no setor...

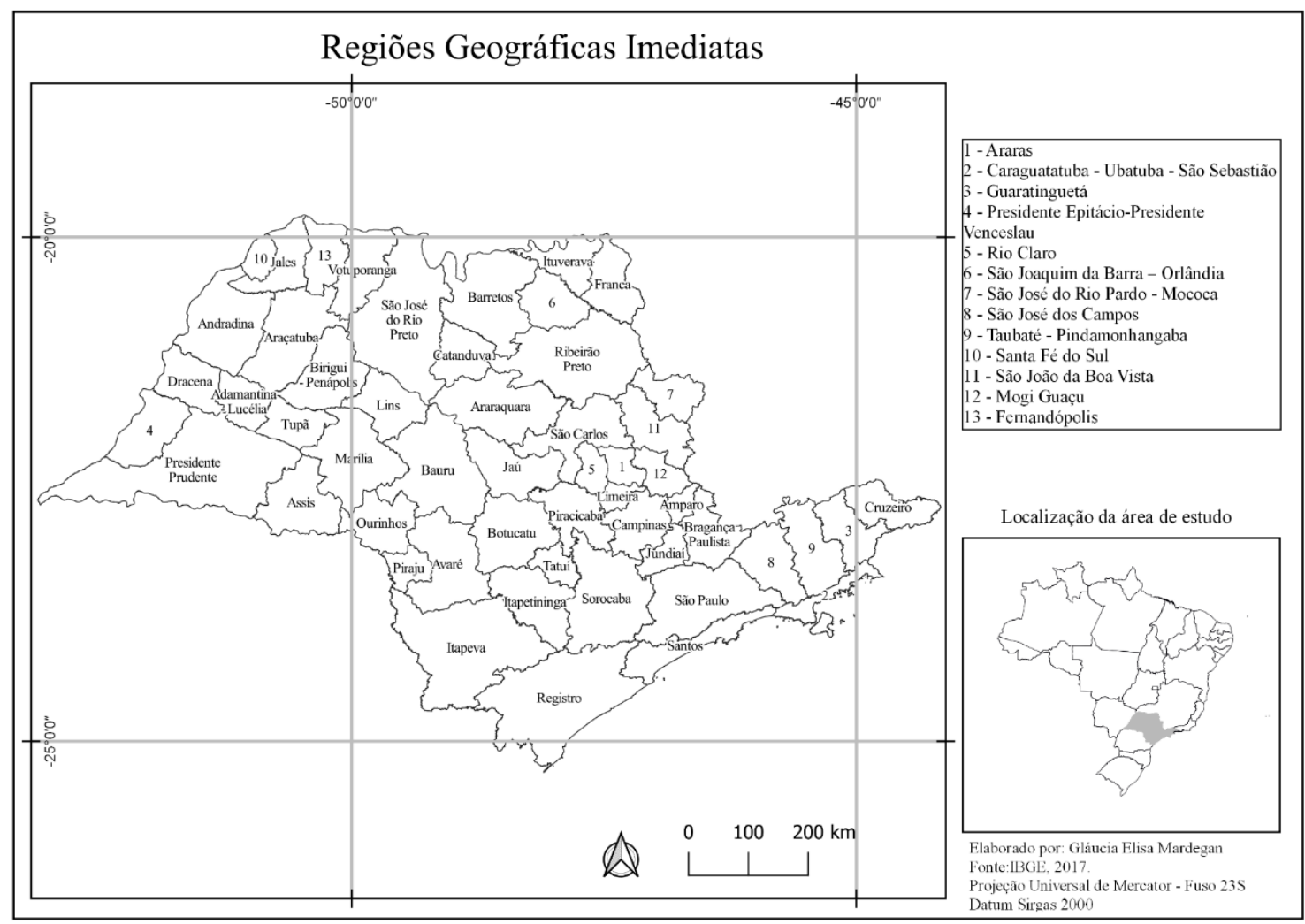

Fonte: IBGE (2017)

MATERIAIS E MÉTODOS

Para o desenvolvimento deste trabalho, além do apoio bibliográfico em autores que trabalham com a temática, para o embasamento teórico, valemonos de coleta e análise de dados secundários, obtidos nos dados da Produção Agrícola Municipal (PAM) do IBGE, respectivamente sobre a produção de canade-açúcar do estado paulista, do Anuário da Cana e UNICA, para os anos de 2006 e 2016 (o ano de 2016, foi o último ano que ocorreu a publicação do Anuário da Cana, e este é importante para confecção dos mapas) para a elaboração de tabelas e mapas.

MUDANÇAS TECNOLÓGICAS DEPOIS DA INICIAÇÃO DO PROTOCOLO AGROAMBIENTAL

ReVISTA Eletrônica da Associação dos GeÓgrafos Brasileiros SeÇÃo Três LagoAs - V. 1, № 34, 2021. 
MARDEGAN, G. E; BACCARIN, J. G. O protocolo agroambiental e as repercussões no setor...

As preocupações ambientais relacionadas com o cultivo de cana-de-açúcar e seu processamento industrial marcou segmentos da sociedade e como consequência trouxe uma necessidade de atuação de agentes públicos, do executivo, ministério público e judiciário. Os empresários do setor e os fornecedores de cana tiveram resistências, por determinado período, mas com o aumento da exportação do etanol e do açúcar, principalmente que era direcionada para a Europa, fez com que, os empresários do setor visem a conservação do meio ambiente como uma qualidade adicional ao vender seus produtos.

Foram se estabelecendo leis e normativos em relação à queimada, alguns procuradores de justiça e juízes agiram mais efetivamente para sua eliminação, na década de 1990, mas a queimada continuou significativa até 2006 em São Paulo. No plano federal, o Código Florestal, lei com primeira edição de 15 de setembro de 1965, no capítulo IV, art. 16, versa sobre a eliminação da queimada nas lavouras (BRASIL, 1965). Mais adiante, o Decreto n. 2.661, de 8 de julho de 1998, estabeleceu normas mais específicas para a eliminação das queimadas nos canaviais.

Em âmbito estadual, São Paulo com o Decreto n. 42.056, de 6 de agosto de 1997, foi sancionado para que a queimada da palha da cana fosse abolida, gradualmente, em áreas mecanizáveis (com declive inferior ou igual a 12\%), no prazo máximo de oito anos e, em área não mecanizável (declividade superior a 12\%), em 15 anos (OLIVEIRA, 1999), porém, com resistência empresarial. A Assembleia Legislativa do Estado de São Paulo (ALESP), através da Lei 11. 241, de 19 de setembro de 2002, estabeleceu que a extinção completa da queimada dos canaviais ocorresse até 2031, em áreas não mecanizáveis ou em imóveis menores que 150 ha, e em áreas mecanizáveis ou acima de 150 ha, até 2021, (ALESP, 2002). Deste modo, a legislação paulista, em vigor, é comedida, com 
MARDEGAN, G. E; BACCARIN, J. G. O protocolo agroambiental e as repercussões no setor...

prazos de no máximo de 20 ou 30 anos, a partir de 2002, o banimento total da queimada da palha (BACCARIN e SILVA, 2015).

Na virada dos séculos XX e XXI, a queimada continuava predominando nos canaviais paulistas (VEIGA FILHO, 1998). A justificativa dos empresários do setor a situação, era a garantia da ocupação de milhares de trabalhadores rurais, os cortadores de cana-de-açúcar. Ao mesmo tempo, como notabiliza Veiga Filho (1998), várias empresas não possuíam o capital necessário para investir nas máquinas necessárias para a colheita mecânica e constatavam dificuldades técnicas e operacionais para a nova prática.

Além das colhedoras, as empresas precisavam adquirir máquinas e equipamentos auxiliares, como o caminhão oficina e carro pipa, para conserto e lavagem das colhedoras no campo, carretas de transbordo e caminhões com carroceria apropriada para o transporte de cana picada. Também se tornaram necessárias adaptações na recepção, lavagem e processamento da cana nas agroindústrias. A limpeza da cana inteira queimada era feita com o uso de grande quantidade de água e a limpeza da cana em tolete passou a ser feita com ventilação, tendo que se investir nas chamadas mesas de $45^{\circ}$ e potentes ventiladores para retiradas das impurezas vegetais (palha) e minerais (terra) (BACCARIN, 2019 , n.p.).

Paes (2007) mostra que, de 18\% do total de área colhida em São Paulo, em 1997, a colheita mecânica avançou para 40\%, em 2006. Com as mobilizações da sociedade civil e ações de parte da burocracia pública em favor da extinção da queimada. A partir de 2006 o discurso dos empresários do setor sucroenergético mudou. Verificou-se a "intensificação do discurso ambientalista atrelado ao aquecimento global" (SAMPAIO, 2019, p. 36), o que culminou com a assinatura 
MARDEGAN, G. E; BACCARIN, J. G. O protocolo agroambiental e as repercussões no setor...

do Protocolo Agroambiental'3, em 2007. Nota-se que os prazos estabelecidos no Protocolo para eliminação das queimadas eram 7 e 14 anos, menor período do que os previstos na Lei estadual de 2002.

A adesão ao Protocolo Agroambiental era voluntária, tendo que ser renovada a cada ano. As usinas que aderissem e cumprissem suas determinações, em especial o calendário de extinção gradativa da queimada de cana-de-açúcar, recebiam o Certificado Etanol Verde. Este vinha conforme os interesses dos empresários e suas perspectivas, à época, de aumento da exportação do etanol, em especial para países, com legislações ambientais mais exigentes.

Após 2007, a colheita mecânica de cana crua (sem queimar) teve adoção acelerada, alcançando 72\% dos canaviais paulistas, em 2012, e 96\%, em 2017 (CONAB, 2008). Além da questão ambiental, outros fatores contribuíram para este fato. Um deles, o aumento da capacidade de investimento dos empresários, entre 2003 e 2009, que está atrelada aos melhores preços do açúcar e do etanol, e ao aporte de capitais de origem estrangeira e nacional (BACCARIN, 2019).

Ocorreu mudanças tecnológicas importantes no plantio da cana-deaçúcar, que passou de um sistema semimecanizado para um mecanizado. Os impactos sociais da mecanização na colheita e no plantio foram muito fortes, com a dispensa de mais de 100 mil cortadores de cana e outros trabalhadores braçais, entre 2007 e 2014. Neste período, ainda que tenha aumentado o número de operadores de máquinas, motoristas de caminhões e algumas categorias administrativas, em termos líquidos, o resultado foi negativo com

\footnotetext{
${ }^{3}$ Para mais informações sobre o Protocolo Agroambiental do Setor Sucroenergético Paulista consultar: SÃO PAULO, Estado de (Secretaria do Meio Ambiente). Protocolo Agroambiental do Setor Sucroenergético Paulista: dados consolidados das safras 2007/08 a 2013/14. São Paulo, SEMA, SAA. Dezembro de 2014.
} 
MARDEGAN, G. E; BACCARIN, J. G. O protocolo agroambiental e as repercussões no setor...

redução de 52 mil ou 16,4\% no número de pessoas ocupadas por empresas sucroenergéticas em São Paulo (BACCARIN, 2019).

Outra coisa que aconteceu durante o Protocolo foi o aumento da concentração industrial e fundiária. Um autor que destaca esta questão é Baccarin (2019), que afirma que em 2007, havia empresas que já tinham avançado muito na mecanização da colheita de cana, enquanto outras apresentavam nível de mecanização próximo de zero. Estas tiveram que aportar maiores recursos financeiros, em um prazo muito curto, para cumprirem as metas do Protocolo, não raramente, recorrendo ao endividamento. Diferentemente das empresas pioneiras, seus resultados operacionais na mecanização, em uma fase de aprendizagem, foram menos significativos e o endividamento de muitas delas, cobrou um preço expressivo, após a mudança da conjuntura setorial em 2010. Os números já apresentados mostram que várias usinas deixaram de funcionar, muitas delas passando seus canaviais para as empresas que permaneceram em atividade, um dos fatores que contribuiu para que o nível de concentração industrial sucroenergético aumentasse nos últimos anos.

A concentração industrial tendeu a vir acompanhada da elevação da concentração fundiária, em parte porque unidades produtivas em atividade absorveram canaviais das que ficaram inativas. Outro ponto que Baccarin (2019) destaca é que uma colhedora de cana tem capacidade de operar cerca de 1.500 ha/safra, dificultando a permanência de pequenos e médios agricultores na atividade, mesmo porque os gastos para aquisição de equipamentos para a colheita, normalmente estão acima de suas capacidades de investimento. Ainda que haja a possibilidade de se alugar o maquinário, o que de fato parecer ter predominado é que um número maior de pequenos e médios proprietários 
MARDEGAN, G. E; BACCARIN, J. G. O protocolo agroambiental e as repercussões no setor...

rurais na região canavieira arrendou suas terras para a exploração por grandes fornecedores ou por usineiros.

RAZÕES DA INTEGRAÇÃO VERTICAL USINA-LAVOURA CANAVIEIRA EM SÃO PAULO

A disposição em rede do agronegócio, em diversos circuitos espaciais produtivos, é organizada a partir de "um jogo de relações dialéticas entre o externo e o interno, o novo e o velho e entre o Estado e o mercado" (ELIAS, 2003, p. 41). Segundo Elias (2011, p. 157) “cada commodity possui suas próprias exigências de insumos químicos, serviços, força de trabalho, tecnologia, capital, maquinários, etc., o que resulta em arranjos territoriais produtivos distintos". Essas especificidades, ou características intrínsecas do setor, ou dos produtos são fundamentais para a composição do arranjo espacial que resulta da articulação entre os lugares que acolhem suas diversas etapas produtivas e as relações entre os variados agentes diretamente envolvidos.

O circuito espacial da produção tem enfoque no produto, nas características intrínsecas de cada setor, em seus aspectos técnicos e normativos (CASTILLO e FREDERICO, 2010). As especificidades do setor sucroenergético que condicionam o subsistema de fluxos materiais envolvidos na produção de canade-açúcar, açúcar, etanol e energia elétrica, bem como as consequências no território, direta ou indiretamente envolvidas podem ser sintetizadas em quatro características intrínsecas de acordo com Castillo $(2013,2015)$ : Impossibilidade de estocar a cana-de-açúcar; O ciclo vegetativo-econômico da cana-de-açúcar (semiperenidade da cultura); Flexibilidade para produzir açúcar, etanol anidro ou etanol hidratado; Cogeração de energia elétrica nas unidades produtivas.

No artigo, os autores não utilizaram o termo "sucroalcooleiro", como o setor é muito conhecido, deu-se a preferência em empregar o termo "sucroenergético", pois, tem uma díade justificativa: o abastecimento de veículos, 
MARDEGAN, G. E; BACCARIN, J. G. O protocolo agroambiental e as repercussões no setor...

através do etanol hidratado ou por meio do etanol anidro adicionado à gasolina e a produção de bioeletricidade, a partir do bagaço da cana (CASTILLO, 2015). Uma única matéria-prima com aproveitamento múltiplo, trouxe a necessidade de um novo nome para o setor.

\section{POSIÇÃO DE SÃO PAULO NO RAMO SUCROENERGÉTICO BRASILEIRO}

O crescimento a partir de 1975 deu-se com a ocupação de terras do oeste paulista, sul de Minas Gerais, Triângulo Mineiro, noroeste do Paraná, dos Cerrados do Centro-Oeste (Goiás, Mato Grosso e Mato Grosso do Sul) (MARDEGAN, MIYAMOTO, 2017), conformando uma região competitiva agroindustrial do setor sucroenergético (RCASS), possui características materiais e imateriais que proporcionam maior eficiência (qualidades e custos) e vantagens diferenciais de acesso aos mercados nacional e internacional. Agrega uma série de fatores naturais (condições edafoclimáticas), geoeconômicos (disponibilidade de terras e trabalhadores, logísticas, proximidade de serviços especializados, presença de centros de ensino, pesquisa e desenvolvimento, etc.) e político-normativos-institucionais (incentivos ficais e financeiros, normas ambientas menos restritivas, associações setoriais, etc.) que proporcionam competitividade ao setor (SANTOS et.al., 2019).

A Tabela 1 mostra a evolução do ramo entre 2006/07 e 2016/17. Além da liderança da Região Sudeste, com destaque ao estado de São Paulo. O crescimento da cana tem acontecido sobre áreas de pastagens, afetando a bovinocultura de corte e leite, e de pequena produção familiar, mas também sobre culturas de grãos, como soja, algodão, milho e do leite (CASTILLO, 2009).

A produção de cana-de-açúcar no território brasileiro apresentou aumento de 52,4\%, entre 2006/07 e 2016/17. Esse crescimento foi puxado pela região Centro-Oeste, com 227,8\% a mais de cana, enquanto a região Nordeste, 
MARDEGAN, G. E; BACCARIN, J. G. O protocolo agroambiental e as repercussões no setor...

que era considerada uma "macrorregião açucareira mundial"(SAMPAIO, 2014, p. 496).

Tabela 1: Quantidade produzida, área plantada e produtividade da cana e agroindústrias sucroenergéticas, Brasil, Macrorregiões e São Paulo, 2006/07, 2016/17.

\begin{tabular}{lccc}
\hline \multirow{2}{*}{ Regiões } & \multicolumn{2}{c}{ Safras } & \multicolumn{2}{c}{$\begin{array}{c}\text { Crescimento } \\
\text { no período } \\
\text { no) }\end{array}$} \\
\cline { 2 - 4 } & Quantidade Produzida (1.000 toneladas) * \\
\hline Brasil & 427.658 & 651.841 & 52,4 \\
Sudeste & 299.712 & 432.410 & 44,2 \\
São Paulo & 264.339 & 365.990 & 38,4 \\
Brasil & Área Plantada (hectares)** & \\
Sudeste & 6.390 .474 & 10.233 .258 & 60,1 \\
São Paulo & 4.155 .564 & 6.698 .849 & 61,2 \\
& 3.495 .893 & 5.686 .134 & 62,6 \\
Brasil & Agroindústrias*** & 38,9 \\
\hline São Paulo & 298 & 414 & 14,4 \\
\hline
\end{tabular}

Fonte: $\left({ }^{*}\right)$ UNICA; $\left({ }^{* *}\right)$ PAM/IBGE; $\left({ }^{* *}\right)$ Anuário da Cana. Elaborada pelos autores.

Em relação à região Sudeste, houve aumento de 44,2\% na quantidade produzida, acima daquele de São Paulo, de 38,4\%. Em 2016/17, do total de área plantada no Sudeste, $84,9 \%$ foram originados do estado paulista, que se mantém como principal produtor de cana-de-açúcar do território brasileiro. Das 651.841 mil toneladas, produzidas no território nacional, 56\% tiveram origem no estado paulista, em 2016/17. Essa distinção de São Paulo, em relação às demais unidades da federação na participação da produção canavieira, começou a ser estabelecia a partir de 1930 (MESQUITA; CASTILLO; LOURENÇO, 2019).

São Paulo possui a centralidade no setor sucroenergético. Esta particularidade aparece em dois níveis, no comando político da produção, resultado em especial do papel da capital paulista como sede de grandes grupos 
MARDEGAN, G. E; BACCARIN, J. G. O protocolo agroambiental e as repercussões no setor...

empresariais do setor, que centraliza parte das decisões que afetam diretamente as diversas unidades que compõe suas topologias; e no sistema de geração de tecnologias e conhecimentos ou comando técnicos de produção (MESQUITA; CASTILLO; LOURENÇO, 2019). Castillo (2009) fala da hegemonia paulista com os polos de produção do conhecimento científico:

que se estende também para o segmento agrícola, para o desenvolvimento biotecnológico (instituições públicas e privadas, tais como o Instituto Agronômico de Campinas e o Centro de Tecnologia Canavieira) e para o segmento de bens de capital do setor, com destaque para os municípios de Piracicaba e Sertãozinho, que concentram a maior parte das indústrias e dos serviços de manutenção de usinas (CASTILLO, 2009, p. 3)

O desenvolvimento de bens de capital específicos para usinas é de grande importância na montagem das unidades e na prestação de serviços de manutenção dos equipamentos. As cidades interioranas de Piracicaba, Sertãozinho, Catanduva e Ribeirão Preto têm nos seus arredores, grande número de indústrias e prestadoras de serviços, a maioria direcionada ao mercado sucroenergético (CASTILLO, 2009).

O local onde se cria o conhecimento assume maior grau de centralidade no âmbito de decisões estratégicas pioneiras (MESQUITA, 2016), que são transmitidas para outras regiões. Essas questões fazem com que São Paulo continue como centro do agronegócio canavieiro, não apenas em termos da produção propriamente dita, mas também no que diz a respeito ao comando e as decisões estratégicas, bem como à capacidade de formação de ativos específicos (MESQUITA, CASTILLO, LOURENÇO, 2019).

\section{A ESPACIALIZAÇÃO DO SETOR SUCROENERGÉTICO PAULISTA}


MARDEGAN, G. E; BACCARIN, J. G. O protocolo agroambiental e as repercussões no setor...

A mudança no número de usinas e grupos e na capacidade de produção resultou em múltiplas modificações na espacialização sucroalcooleira. Em conformidade com Corrêa (2012), o arranjo regional da cana-de-açúcar destacase pelo ritmo, que vem acompanhado de variados projetos e pelo protagonismo das corporações multinacionais de origem estrangeira.

Em 2006, conforme a Figura 2, nas Regiões Geográficas Imediatas próximas ao litoral paulista, como Registro, Santos, Caraguatatuba/ Ubatuba/São Sebastião, Guaratinguetá, Pindamonhangaba, Cruzeiro, a presença do ramo sucroalcooleiro era praticamente nula. O mesmo acontecia em algumas do interior, como Itapeva, Jundiaí, São José dos Campos, Taubaté e Marília. Por outro lado, a RGI de Ribeirão Preto destacava-se pelo grande número de usinas e pela área colhida de cana. Outras regiões próximas à Ribeirão Preto também apresentavam forte participação na produção setorial, citando-se Catanduva, Araraquara e Barretos.

Em 2016 (Figura 3), o quadro do setor sucroenergético apresentava duas situações que chamavam a atenção, o aumento de número de usinas paradas ou em recuperação judicial. "Os grupos menos capitalizados, modernos e competitivos são na maioria, os que se encontram em situação de recuperação judicial e falência" (SANTOS, 2019).

Em 2006 (Figura 2), as RGI com maior destaque, estavam próximas aos centros de pesquisa e manutenção, ou eram áreas tradicionais no plantio da cana. Merece destaque a região de Ribeirão Preto, com 23 unidades, e as regiões que são suas vizinhas, como Araraquara, Catanduva, Barretos, São Carlos. Depois destaque para a região de Piracicaba, Jaú, Sorocaba e Campinas. As regiões localizadas ao norte do estado também possuíam a presenças de unidades produtivas, como São José do Rio Pardo, Araçatuba Andradina e Birigui - Penápolis. 
MARDEGAN, G. E; BACCARIN, J. G. O protocolo agroambiental e as repercussões no setor...

Figura 2: Mapa da área colhida (ha) por usina e sua localização (2006).

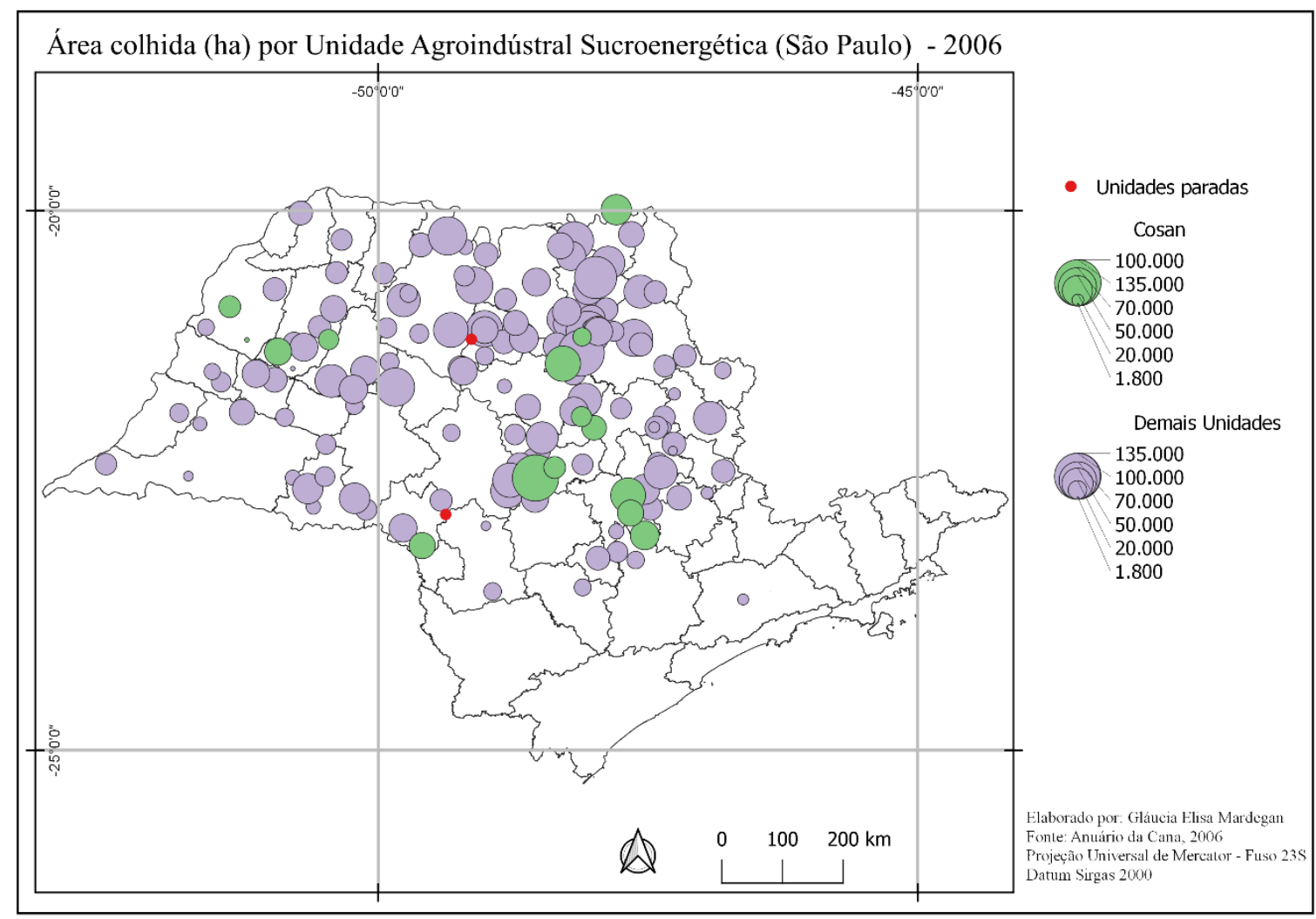

Fonte: Anuário da Cana (2006): Elaborado por: Gláucia Elisa Mardegan

Observou-se na safra de 2016 (Figura 3), um composto de regiões que perderam usinas e outras obtiveram aumento no número de unidades produtivas. A região de Ribeirão Preto reduziu algumas unidades, enquanto as regiões limítrofes de Jaú e São Carlos elevaram o número. São José do Rio Pardo também aumentou uma unidade.

Figura 3: Mapa da área colhida (ha) por usina e sua localização (2016) 
MARDEGAN, G. E; BACCARIN, J. G. O protocolo agroambiental e as repercussões no setor...

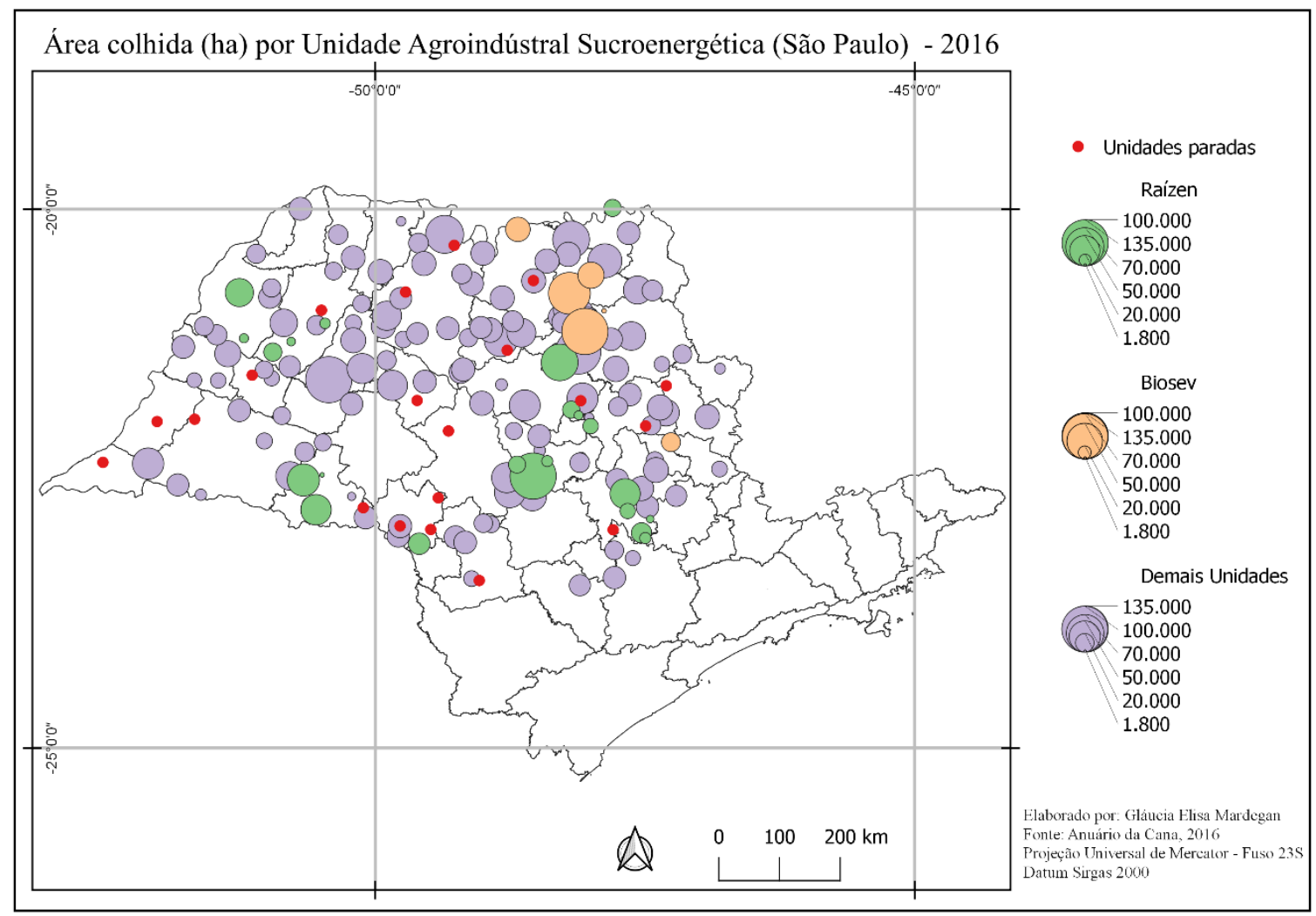

Fonte: Anuário da Cana (2016). Elaborado por: Gláucia Elisa Mardegan

\section{CONSIDERAÇÕES FINAIS}

Com o apoio bibliográfico e os dados secundários, foi possível apresentar ideias neste artigo, que buscam contribuir para reconhecer os principais fatores responsáveis pela mecanização do setor sucroenergético e identificar a expansão geográfica das UAS pelo território paulista e quais foram as Regiões Geográficas Imediatas tiveram maior expansão do setor.

Leis estaduais e federais, e o Protocolo Agroambiental, acordado entre o setor sucroenergético e público, foram responsáveis por acelerar o processo de mecanização do setor sucroenergético, e com consequências sociais graves, como o aumento do desemprego estrutural. As características intrínsecas da cultura são responsáveis pelo processo de espacialização das suas indústrias e de algumas dinâmicas do processo produtivo. 
MARDEGAN, G. E; BACCARIN, J. G. O protocolo agroambiental e as repercussões no setor...

A expansão das UAS no estado de São Paulo, entre 2006 e 2016 foi muito influenciada pelo aparecimento de grupos no setor, formados por empresas estrangeiras e por nacionais. Essa expansão ocorreu através de regiões que já eram tradicionais no cultivo de cana-de-açúcar, para regiões que estão contíguas a elas, ocorrendo a substituição de culturas agrícolas pela cana-de-açúcar. Essa expansão da cana transforma a paisagem e a dinâmica espacial, ocasionado uma rigidez nas áreas que possuem maior percentual desta cultura agrícola.

\section{AGRADECIMENTO}

Gostaria de agradecer a Coordenação de Aperfeiçoamento de Pessoal de Nível Superior (CAPES) pelo apoio financeiro a minha pesquisa de doutorado, na qual, este trabalho deriva.

\section{REFERÊNCIAS BIBLIOGRÁFICAS}

ALESP (Assembleia Legislativa do estado de São Paulo). Texto da Lei n. 11.241, de 19 de setembro de 2002. Disponível em: www.al.sp.gov.br. Acesso em: 20 jun. 2021.

BACCARIN, José Giacomo; DA SILVA, Denise Boito Pereira. Meio ambiente versus emprego: impactos de transformações tecnológicas na ocupação canavieira no Estado de São Paulo, Brasil, 2007 a 2013. Cadernos CERU, v. 25, n. 2, p. 13-38, 2014.

BACCARIN, José Giacomo. Expansão e mudanças tecnológicas no agronegócio canavieiro: impactos na estrutura fundiária na ocupação agropecuária no estado de São Paulo. São Paulo: Editora Unesp Digital, 2019. E-Book. ISBN 978-85954633-4-9. Disponível em: <https://www.book7.com.br/expans-o-e-mudancastecnologicas-no-agronegocio-canavieiro.html>. Acesso em: 20 jun. 2021.

BACCARIN, José Giacomo. Expansão e mudanças tecnológicas no agronegócio canavieiro: impactos na estrutura fundiária na ocupação agropecuária no estado de São Paulo. São Paulo: Editora Unesp Digital, 2019. E-Book. ISBN 978-85- 
954633-4-9. Disponível em: <https://www.book7.com.br/expans-o-e-mudancastecnologicas-no-agronegocio-canavieiro.html>. Acesso em: 20 jun. 2021.

BRASIL. Lei n 4. 771, de 15 de setembro de 1965. Institui o Novo Código Florestal. Disponível em: <http://www.planalto.gov.br/ccivil_03/leis/l4771.htm>. Acesso em: 12 jun. 2021.

BRASIL. Lei n 4. 771, de 15 de setembro de 1965. Institui o Novo Código Florestal. Disponível em: <http://www.planalto.gov.br/ccivil_03/leis//4771.htm>. Acesso em: 12 jun. 2021.

CASTILLO, Ricardo. A expansão do setor sucroenergético no Brasil. In: BERNARDES, Júlia Adão; SILVA, Catia Antônia da; ARRUZZO, Roberta Carvalho (org.). Espaço e energia: mudanças no paradigma sucroenergético. Rio de Janeiro: Lamparina, 2013. p. 75-84.

CASTILLO, Ricardo. Expansão do setor sucroenergético no Brasil: competitividade regional e expansão para o bioma Cerrado, GEOgraphia, Niterói, ano 17, n. 35, p. 95-119, 2015.

CASTILLO, Ricardo. Região competitiva e circuito espacial produtivo: a expansão do setor sucroalcooleiro (complexo cana-de-açúcar) no território brasileiro. Anais do $12^{\circ}$ Encontro de Geógrafos da América Latina (EGAL) - Montevidéu, 3-7 abr. 2009. Disponível em: http://observatoriogeograficoamericalatina.org.mx/egal12/Geografiasocioecono mica/Geografiaespacial/60.pdf. Acesso em: 20 jun. 2021.

CASTILLO, Ricardo; FREDERICO, Samuel. Espaço geográfico, produção e movimento: uma reflexão sobre o conceito de circuito espacial produtivo. Sociedade \& Natureza, Uberlândia, V.22, n.3: 461-474, dez. 2010.

CONAB (COMPANHIA NACIONAL DE ABASTECIMENTO). Perfil do setor do açúcar e do álcool no Brasil - situação observada em novembro de 2007 a abril de 2008. Brasília: Conab, 2008.

CORRÊA, Domingos Sávio. Fusões e aquisições nos segmentos carne bovina, óleo de soja e sucroalcooleiro (1992-2010). Tese de Doutorado. Universidade de São Paulo.

ELIAS, Denise. Agronegócio e novas regionalizações no Brasil. Revista Brasileira de Estudos Urbanos e Regionais, v. 13, n. 2, p. 153-153, 2011. 
ELIAS, Denise. Globalização e Agricultura. São Paulo: EdUSP, 2003.

ELIAS, Denise. Regiões produtivas do agronegócio: notas teóricas e metodológicas. In: BERNARDES, Júlia Adão; SILVA, Catia Antônia da; ARRUZZO, Roberta Carvalho (org.). Espaço e energia: mudanças no paradigma sucroenergético. Rio de Janeiro: Lamparina, 2013. p. 201-220.

IEA (INSTITUTO DE ECONOMIA AGRÍCOLA DO ESTADO DE SÃO PAULO). Banco de dados. Disponível em: <http://www.iea.sp.gov.br>. Acesso em: 23 jun. 2021.

Instituto Brasileiro de Geografia e Estatística (IBGE). Produção Agrícola Municipal: culturas temporárias e permanentes. Rio de Janeiro: IBGE, 2019. 24 p. Disponível em:

<https://biblioteca.ibge.gov.br/visualizacao/periodicos/66/pam_2019_v46_br_not as_tecnicas.pdf $>$. Acesso em: 01 jun. 2021.

MARDEGAN, Gláucia Elisa; MIYAMOTO, Bruno Cesar Brito. A monocultirização da cana-de-açúcar e sua expansão pelo território brasileiro. In: XII ENCONTRO NACIONAL DA ANPEGE - XII ENANPEGE, XII, 2017, Porto Alegre - RS. Anais eletrônico... Porto Alegre: [s. n.], 2017. p. 538 - 549. Disponível em: http://www.enanpege.ggf.br/2017/anais/arquivos/GT\%2003/69.pdf. Acesso em: 28 jun. 2021.

MESQUITA, Fernando Campos; CASTILLO, Ricardo; LOURENÇO, Taiana Ciscotto Martins. A centralidade paulista no agronegócio canavieiro do Centro-Sul do Brasil. In: BERNARDES, Júlia Adão; CASTILLO, Ricardo (org.). Espaço Geográfico e Competitividade. Rio de Janeiro: Lamparina, 2019. p. 39-60.

OLIVEIRA, Ana Maria Soares de. Perspectivas sobre o setor sucroalcooleiro frente à redução da queimada de cana-de-açúcar, a intensificação do corte mecanizado e a certificação socioambiental. Presidente Prudente, 1999. Disponível em: $<$ https://www.agencia.cnptia.

embrapa.br/Repositorio/Perspectivas_setor_sucoalcooleiro_000fjablj0y02wyiv80 9gkz51gf7ldgy.pdf>. Acesso em: 12 jun. 2021.

PAES, Luiz Antônio Dias. Emissões na queimada da cana; controle. In: MACEDO, I. de C. (Org.). A energia da cana-de-açúcar - doze estudos sobre a agroindústria da cana-de-açúcar no Brasil e sua sustentabilidade. 2. Ed. São Paulo: UNICA, 2007. p.85-91. 
SAMPAIO, Mateus de Almeida Prado. Mercado sucroenergético mundial: dinâmicas do início do século XXI. In: BERNARDES, Júlia Adão; CASTILLO, Ricardo. Espaço Geográfico e Competitividade: regionalização do setor sucroenergético no Brasil. Rio de Janeiro: Lamparina, 2019. p. 17-38.

SAMPAIO, Mateus de Almeida Prado. $360^{\circ}$ - o périplo do açúcar em direção à macrorregião canavieira do Centro-Sul do Brasil. 2014. 881 f. Tese (Doutorado) Curso de Geografia, Faculdade de Filosofia, Letras e Ciências Humanas, Universidade de São Paulo, São Paulo, 2014. Disponível em: https://www.teses.usp.br/teses/disponiveis/8/8136/tde-11092015-154508/ptbr.php. Acesso em: 19 jun. 2021.

SANTOS, Henrique Faria dos et al. Competitividade do setor sucroenergético no Brasil. In: BERNARDES, Júlia Adão; CASTILLO, Ricardo. Espaço Geográfico e Competitividade: regionalização do setor sucroenergético no brasil. Rio de Janeiro: Lamparina, 2019. p. 61-90.

SANTOS, Milton; SILVEIRA, Maria Laura. O Brasil: território e sociedade no início do século XXI, Rio d Janeiro: Record, 2001.

SÃO PAULO, Estado de (Secretaria do Meio Ambiente). Protocolo Agroambiental do Setor Sucroenergético Paulista: dados consolidados das safras 2007/08 a 2013/14. São Paulo, SEMA, SAA. Dezembro de 2014.

UNICA - União da indústria da cana-de-açúcar. Disponível em: <www.unica.br>. Diversos acessos: 2006, 2012, 2017.

VEIGA FILHO, Alceu de Arruda. Mecanização da colheita da cana-de-açúcar no estado de São Paulo: uma fronteira de modernização tecnológica da lavoura. Campinas, 1998. 127f. Dissertação (Mestrado em Política Científica e Tecnológica) - Instituto de Geociências, Universidade Estadual de Campinas. Campinas, 1998. 